\title{
EDITORIAL
}

\section{A Pesquisa e o Campo da Saúde Coletiva}

O tema deste número de Physis traz um conjunto de reflexões sobre o campo da Saúde Coletiva, segundo alguns de seus atores mais relevantes. $\mathrm{Na}$ abertura, Everardo Nunes traça um panorama tanto histórico quanto epistemológico da constituição da área de Saúde Coletiva como campo acadêmico e político em nosso país. Entre os vários aspectos ressaltados por Nunes, destaco a interdisciplinaridade e as interconexões entre academia e diversos níveis da burocracia estatal, que deram ao campo uma face bastante peculiar em nosso país. Isto se revestirá de importância especial na argumentação de outros artigos deste número, como veremos a seguir.

Na sequiência, Madel Luz propõe uma reflexão sobre o próprio conceito de "produtividade", pedra-de-toque de todos os processos de avaliação científica e acadêmica, incluindo-se os que ocorrem em nosso meio. Luz expõe em seu texto como aspectos contingentes da estruturação das áreas de pesquisa e seus respectivos comitês de avaliação em nosso país tornam-se determinantes na formatação final dos critérios de avaliação, naturalizados em sua aparente objetividade.

O artigo seguinte, de Sandra Caponi e Fernanda Rabelo, articula temas dos artigos precedentes; por um lado, mostra que a fundante característica interdisciplinar do campo constitui desafio complexo para as propostas de avaliação, colocando em questão a existência de uma métrica neutra para a mesma, dentro da concepção de produtividade já criticada por Luz em seu texto. Caponi e Rabelo se apóiam em Toulmin, recolhendo deste a crítica à concepção de uma racionalidade que como deus ex-machina opera algoritmicamente, além de qualquer referência histórica ou social - ou seja, humana - para destacar que, dada a heterogeneidade interna da própria área, a adoção de critérios do tipo one size fits all talvez não capture adequadamente essa riqueza teórica, metodológica e disciplinar, chegando mesmo a colocá-la em risco, tendo em vista o papel determinante que os processos oficiais de avaliação têm na própria conformação institucional do campo.

Por fim, o artigo escrito a quatorze mãos por Ligia Kerr-Pontes et al., que teve seu embrião num manifesto apresentado ao Fórum de Coordenadores 
de Pós-graduação em Saúde Coletiva no primeiro semestre deste ano, discute especificamente a lógica da avaliação dos cursos de pós-graduação. KerrPontes e colaboradores buscam explicitar determinadas concepções epistemológicas implícitas na lógica dos processos de avaliação, a começar pelo que se supõe que seja "ciência", discutindo ainda possíveis consequiências indesejáveis de estratégias de hierarquização rígida do campo, como a inviabilização da continuidade de parcela considerável dos programas de pósgraduação (e, conseqüentemente, de pesquisa) existentes no país, precisamente pela aplicação, como descrita por Luz, "mais realista que o rei”, de regras institucionais tomadas como leis inexoráveis.

Nossa escolha de tema foi propositalmente polêmica; os autores convidados não concordam necessariamente entre si, e algumas das teses apresentadas na discussão podem sofrer objeções razoáveis por parte de outros a(u)tores igualmente representativos do campo. Fundamentalmente, contudo, nosso objetivo é chamar à tona o debate sobre a estruturação interna do próprio campo da Saúde Coletiva e os processos de avaliação sobre o mesmo. Entendemos - e este é um ponto comum a todos os autores que participam deste tema - que a avaliação do que se produz com recursos públicos é uma necessidade ética e politicamente indiscutível. Parece-nos, contudo, que tais processos vêm sendo implantados sem a devida reflexão epistemológica e política sobre os mesmos, o que é, a nosso ver, um problema para a ciência em geral mas em particular para um campo que tem como traços fundadores e fundamentais exatamente a reflexão crítica e o compromisso político. Preocupanos, por exemplo, que sólidos e tradicionais programas de pós-graduação na área estejam seriamente considerando a fragmentação de suas pós-graduações em cursos de Epidemiologia, Ciências Sociais e Planejamento, para melhor se adaptarem às normas de avaliação vigentes, contrariando a própria trajetória histórica do campo, como se vê no artigo de Nunes.

Não é qualquer campo do conhecimento que pode se dar ao luxo de tal meta-reflexão sobre si próprio; acreditamos que Physis, como revista de e para a Saúde Coletiva, cumpre sua missão ao se propor, para usar uma expressão tomada de Foucault, como superfície de emergência para proposição desse debate.

A vocação de chamamento à reflexão e ao debate está presente também na seção de temas livres, aberta por artigo de Maria Lucia Penna, que faz importante contribuição à discussão sobre a interrupção da gravidez nos casos 
de feto anencefálico, mostrando como o consenso sobre a morte cerebral já seria em si um amparo ético e jurídico suficiente para o procedimento, tendo-se contudo no momento uma interdição em nosso país até mesmo da discussão do tema, fundamentalmente devido à pressão de grupos religiosos organizados que contrariam nessa ação a própria concepção moderna de um Estado laico.

Segue-se artigo de Cynthia Sarti, sobre o atendimento de vítimas da violência em serviços de emergência, a partir de uma perspectiva antropológica. Por fim, a seção encerra-se com artigo de Martinho Silva sobre a noção de responsabilidade e suas repercussões no campo da atenção em Saúde Mental, com implicações que se estendem para além das fronteiras dessa área específica da atenção à saúde. Objetos e temas todos, como se vê, cuja importância se estende para além dos territórios mapeados em cada um dos artigos.

A seção de resenhas traz os comentários de Paula Lacerda sobre $O$ Rei da Lapa: Madame Satã e a Malandragem Carioca: uma história de violência no Rio de Janeiro dos anos 30-50, de Gilmar Rocha, seguida do texto de João Marcelo Ehlert Maia, sobre De olhos bem abertos: rede de tráfico em Copacabana, de Luiz Fernando de Almeida Pereira; as análises de Cláudia S. Pereira sobre De Perto Ninguém é Normal, de Miriam Goldenberg e finalmente, André A. Brandão e Mani T. A. de Marins fecham a seção e este número de Physis, com sua crítica sobre $O$ Curso do Rio: Um estudo sobre ação afirmativa no acesso à universidade, de William Bowen e Derek Bok.

KENNETHROCHEL DECAMARGOJR. 